le portiQue $\begin{array}{ll}\text { Le Portique } \\ \text { Revue de philosophie et de sciences humaines }\end{array}$

4 | 1999

Eduquer : un métier impossible?

\title{
L'institution oubliée
}

\section{Alain Finkielkraut}

\section{OpenEdition}

\section{Journals}

\section{Édition électronique}

URL : http://journals.openedition.org/leportique/280

DOI : 10.4000/leportique.280

ISSN : $1777-5280$

\section{Éditeur}

Association "Les Amis du Portique"

Édition imprimée

Date de publication : 1 septembre 1999

ISSN : 1283-8594

Référence électronique

Alain Finkielkraut, «L'institution oubliée », Le Portique [En ligne], 4 | 1999, mis en ligne le 11 mars 2005, consulté le 26 mars 2021. URL : http://journals.openedition.org/leportique/280 ; DOI : https://doi.org/ 10.4000/leportique.280

Ce document a été généré automatiquement le 26 mars 2021.

Tous droits réservés 


\title{
L'institution oubliée
}

\author{
Alain Finkielkraut
}

1 S'il m'était un jour donné de faire un cours d'instruction civique à des élèves de première, je devrais commencer par m'inscrire en faux contre les principes officiellement invoqués pour justifier la création d'un tel cours.

2 En réponse à la violence, qui se propage dans les cités comme dans les lycées, il faut, nous dit le ministère de l'Éducation, apprendre aux « jeunes » le respect de l'Autre. Cet objectif, irréprochable, conçoit toutes les relations humaines sur le modèle de l'intersubjectivité ou du dialogue des consciences. Or, le lien social n'est pas seulement dialogique : aux rapports intersubjectifs s'ajoutent les rapports institutionnels.

3 L'école, par exemple, ne met pas aux prises des subjectivités libres et qui dialoguent comme au café, elle est le lieu où se rencontrent des élèves et des professeurs, c'est-àdire des partenaires qui doivent faire des choses différentes et dont les rôles sont fixés par une règle établie à l'avance. De cette règle, de ces distinctions, et de ces couples institutionnels, le respect de l'Autre ne laisse rien subsister. Tout le monde, en effet, étant l'Autre de chacun, les places deviennent interchangeables et les rôles réversibles. Les différences s'abîment dans une homogénéité sans remède. Présenté avec emphase comme l'alternative à la haine, le respect de l'Autre est le visage affable de la muflerie, la version douce du rejet des formes et de la haine de l'institution.

4 On insiste aussi dans les hautes sphères sur la vertu de tolérance, et l'on cite beaucoup, ces derniers temps, Nathan le Sage. À juste titre: qui souhaiterait revenir à l'époque obscure où sévissait le principe d'autorité ? Cependant, le problème actuel de l'école, ce n'est pas l'absence de pluralisme, c'est bien plutôt la dissolution de la culture dans le pluralisme des convictions. L'instruction civique doit contribuer à résoudre ce problème, non à l'aggraver. Que la démocratie est le meilleur régime, mais que la démocratie n'est pas le dernier mot de toute chose : voilà, sans doute, un beau sujet de leçon.

5 Mais plus encore qu'avec l'esprit du ministère, l'instruction morale et civique doit impérativement rompre avec l'esprit du temps: l'esprit du temps, en effet, est sociologique. Il affirme que les comportements humains sont déterminés par la société. Aussi impute-t-il spontanément les violences urbaines au chômage et à la misère des 
banlieues. Non sans quelque raison : on ne déplore aucun incendie de véhicules avenue Foch, rue Guynemer ou du côté de Neuilly.

Il n'en reste pas moins que ce qui nous introduit dans le monde moral c'est, comme l'écrit Paul Ricœur, "notre capacité d'imputabilité »: le fait, autrement dit, de nous reconnaître comme l'auteur de nos propres actes, comme celui au compte duquel on peut mettre ces actes. Par le sociologisme, l'humanité échappe à l'imputabilité, et sort, en douce, du monde moral. Dans un cours de morale, je m'abstiendrais donc de prêcher la morale, je m'efforcerais juste de barrer cette sortie.

\section{RÉSUMÉS}

Rompre avec l'esprit du temps... 